\title{
Neuropsychological functioning in acromegaly: towards identification of modifiable factors to improve long-term care after remission
}

\author{
Alberto M. Pereira ${ }^{1}$ \\ Received: 19 August 2015/Accepted: 25 August 2015/Published online: 8 September 2015 \\ (C) Springer Science+Business Media New York 2015
}

Pituitary tumors can be treated effectively in the vast majority of cases. Surgical adenomectomy (mostly transsphenoidal), medical treatment (with dopamine agonists, somatostatin analogs, GH receptor antagonists), radiotherapy, or a combination of these treatment modalities will result in long-term remission rates of more than $90 \%$ [1]. However, despite being considered cured by the medical community because long-term remission has been achieved, many patients with pituitary adenomas encounter persistent morbidity in the face of near normalization of mortality. The morbidity includes both physical and psychological impairments, and is accompanied by reduced quality of life. Therefore, these patients cannot be considered really cured, a feature that has regained much attention, especially during the last decade [2]. The awareness that the effects of the pituitary tumor and/or of its treatment may be long lasting despite cure of the tumor per se raises questions as to the mechanisms responsible for these longlasting effects. It is now generally accepted that hypopituitarism, intrinsic imperfections of endocrine replacement therapy, and persistent effects of previous hormone excess on the central nervous system may all affect long-term morbidity, general well being, and mortality [3].

It cannot be sufficiently emphasized that endocrine control of the central nervous system is fundamental for normal neuropsychological function. Cognition, mood, behavior, and personality may all be affected in patients with pituitary disease, but also by its treatment by

Alberto M. Pereira

a.m.pereira@lumc.nl

1 Division of Endocrinology, Department of Medicine, and Center for Endocrine Tumors Leiden, Leiden University Medical Center, Leiden, The Netherlands disrupting the connections between the prefrontal cortex with other limbic structures, which impairs the behavioral control exerted by the prefrontal cortex on the limbic system [4]. Limbic structures like the hippocampus and the prefrontal cortex, highly express glucocorticoid receptors but are also rich in GH and IGF-1 receptors $[5,6]$. This suggests that these brain structures are also particularly vulnerable in states of severe growth hormone $(\mathrm{GH})$ deficiency, or GH excess as is present in acromegaly. In accordance, impaired cognitive function, psychopathology, and maladaptive personality have all been documented in patients with active acromegaly [7]. In addition, substitution of GH deficient adult patients with recombinant human GH resulted in a rapid and sustained amelioration of cognitive functioning [8].

It has now become apparent that neuropsychological dysfunction may persist in patients treated for pituitary adenomas even after many years of remission. For instance, $36 \%$ of the patients that were considered cured from acromegaly showed elevated scores for anxiety and depression [9]. At present, the number of reported patients that underwent neuropsychological evaluation after being considered adequately treated for acromegaly is still limited. Most studies evaluating cognitive function found worse scores on memory and executive functioning both in patients treated for acromegaly and for non-functioning adenomas, when compared to controls [10-14]. In the cohort of patients successfully treated for acromegaly at our center, cognitive function did not differ between acromegaly patients and matched controls or between acromegaly patients and patients treated for non-functioning adenomas [15]. Differences in the duration of disease remission, and the heterogeneity between the patient groups might explain, at least in part, the differences observed between the studies. 
In addition to cognition, behavior and mood also seem to be affected despite long-term remission. Increased anxiety-related personality traits were found in both uncontrolled and controlled patients with acromegaly and non-functioning adenomas, when compared to healthy controls. In addition, acromegaly was associated with reduced impulsivity and novelty seeking behavior [16]. In accordance, patients considered to be cured from acromegaly from the Leiden series appeared to have more psychopathology and maladaptive personality traits when compared to both patients treated for a non-functioning pituitary tumors and healthy controls [15].

In this issue, Crespo et al. [17] report on important data about decision making in patients with acromegaly and long-term disease control. They observed impaired decision-making strategies, which appeared to be related to affective alterations. These findings are both important and intriguing, first of all because in clinical practice, the finding that decision making and memory are related to anxiety and depression has not yet received sufficient attention. Both anxiety and depression affect cognitive functioning, as can be assessed for instance using the Iowa Gambling Task: two recent reports independently documented a clear association between decision making and psychopathology both in healthy individuals and in patients with anorexia nervosa $[18,19]$. The association is of particular interest because this implies that interventions aimed at improving anxiety and/or depression might improve cognitive performance, and consequently general well being. A recent study in patients with acromegaly even demonstrated superiority of psychopathology over biochemical control in predicting impaired quality of life [20].

In addition, it appears that also other factors like coping strategies and illness perceptions of patients treated for pituitary adenomas are related to psychopathology, and consequently may also affect quality of life after long-term remission. Patients treated for Cushing's disease, for acromegaly, and for non-functioning pituitary adenomas displayed different and less effective coping strategies when compared to controls [21]. Illness perceptions were negatively affected in patients after remission for both acromegaly and Cushing's disease, and were strongly related to quality of life [22].

We all acknowledge with our own subjective experiences in routine clinical practice that there are subtle differences between the personalities of patients cured from acromegaly and those of patients with other pituitary diseases. However, clinical endocrinologists are not trained to detect subtle manifestations of psychopathology and maladaptive personality traits. Therefore, the multidisciplinary approach should not only be reserved for the diagnosis and initial treatment of patients with pituitary adenomas, but also during long-term follow-up, preferably on a periodical basis. Such a multidisciplinary evaluation should include, amongst others, a neuropsychological evaluation after optimal hormone replacement and disease control.

Most importantly, this implicates that treatment goals for the vast majority of patients with pituitary adenomas will shift from long-term cure to long-term care. Further research is therefore needed to get more insight into these factors of influence on neuropsychological functioning, including the extent of reversibility of hormone excess syndromes. The fact that coping strategies are altered despite long-term remission and illness perceptions are affected, strongly suggests that, besides neuropsychological evaluation and care, long-term care should also incorporate self-management interventions that might help improve quality of life.

\section{Compliance with ethical standards}

Conflict of interest A.M. Pereira has received unrestricted grants from Pfizer, Ipsen, and Novartis.

\section{References}

1. S. Melmed, Update in pituitary disease. Rev. J. Clin. Endocrinol. Metab. 93, 331-338 (2008)

2. S.M. Webb, Pituitary tumors: coping with 'cured' pituitary tumors. Nat. Rev. Endocrinol. 7, 251-252 (2011)

3. A.M. Pereira, Long-term effects of treatment of pituitary adenomas. Handb. Clin. Neurol. 124, 361-371 (2014)

4. M.A. Weitzner, Neuropsychiatry and pituitary disease: an overview. Rev. Psychother. Psychosom. 67, 125-132 (1998)

5. Z. Lai, P. Roos, O. Zhai, Y. Olsson, K. Fhölenhag, C. Larsson, F. Nyberg, Age-related reduction of human growth hormone-binding sites in the human brain. Brain Res. 621, 260-266 (1993)

6. E.R. de Kloet, M. Joëls, F. Holsboer, Stress and the brain: from adaptation to disease. Nat. Rev. Neurosci. 6, 463-475 (2005)

7. S. Richert, A. Strauss, R. Fahlbusch, R. Oeckler, K. von Werder, Psychopathologic symptoms and personality traits in patients with florid acromegaly. Schweiz. Arch. Neurol. Psychiatr. 138, 61-86 (1987)

8. L.I. Arwert, D.J. Veltman, J.B. Deijen, P.S. van Dam, M.L. Drent, Effects of growth hormone substitution therapy on cognitive functioning in growth hormone deficient patients: a functional MRI study. Neuroendocrinology 83, 12-19 (2006)

9. N.R. Biermasz, S.W. van Thiel, A.M. Pereira, H.C. Hoftijzer, A.M. van Hemert, J.W. Smit, J.A. Romijn, F. Roelfsema, Decreased quality of life in patients with acromegaly despite long-term cure of growth hormone excess. J. Clin. Endocrinol. Metab. 89, 5369-5376 (2004)

10. P. Brummelman, J. Koerts, R.P. Dullaart, G. van den Berg, O. Tucha, B.H. Wolffenbuttel, A.P. van Beek, Effects of previous growth hormone excess and current medical treatment for acromegaly on cognition. Eur. J. Clin. Invest. 42, 1317-1324 (2012)

11. J.F. Martín-Rodríguez, A. Madrazo-Atutxa, E. Venegas-Moreno, P. Benito-López, M.Á. Gálvez, D.A. Cano, F.J. Tinahones, E. Torres-Vela, A. Soto-Moreno, A. Leal-Cerro, Neurocognitive function in acromegaly after surgical resection of $\mathrm{GH}$-secreting adenoma versus naïve acromegaly. PLoS One 4(8), e60041 (2013) 
12. C. Sievers, P.G. Sämann, H. Pfister, C. Dimopoulou, M. Czisch, J. Roemmler, J. Schopohl, G.K. Stalla, J. Zihl, Cognitive function in acromegaly: description and brain volumetric correlates. Pituitary 15, 350-357 (2012)

13. C.G. Yedinak, M. Fleseriu, Self-perception of cognitive function among patients with active acromegaly, controlled acromegaly, and non-functional pituitary adenoma: a pilot study. Endocrine 46, 585-593 (2014)

14. K. Müssig, B. Besemer, R. Saur, S. Klingberg, H.U. Häring, B. Gallwitz, T. Leyhe, Deteriorated executive functions in patients with successful surgery for pituitary adenomas compared with other chronically ill patients. J. Int. Neuropsychol. Soc. 17, 369-375 (2011)

15. J. Tiemensma, N.R. Biermasz, R.C. van der Mast et al., Increased psychopathology and maladaptive personality traits, but normal cognitive functioning, in patients after long-term cure of acromegaly. J. Clin. Endocrinol. Metab. 95, E392-E402 (2010)

16. C. Sievers, M. Ising, H. Pfister, C. Dimopoulou, H.J. Schneider, J. Roemmler, J. Schopohl, G.K. Stalla, Personality in patients with pituitary adenomas is characterized by increased anxiety-related traits: comparison of 70 acromegalic patients with patients with non-functioning pituitary adenomas and age- and gender-matched controls. Eur. J. Endocrinol. 160, 367-373 (2009)

17. I. Crespo, A. Santos, E. Valassi, P. Pires, S.M. Webb, E. Resmini, Impaired decision-making and delayed memory are related with anxiety and depressive symptoms in acromegaly. Endocrine (2015). doi:10.1007/s12020-015-0634-6
18. L. de Visser, L.J. van der Knaap, A.J. van de Loo, C.M. van der Weerd, F. Ohl, R. van den Bos, Trait anxiety affects decisionmaking differently in healthy men and women: towards genderspecific endophenotypes of anxiety. Neuropsychologia 48, 1598-1606 (2010)

19. L. Fornasari, G. Gregoraci, M. Isola, G.A. Laura Negri, G. Rambaldelli, S. Cremaschi, L. Faleschini, F. Canalaz, L. Perini, M. Balestrieri, F. Fabbro, P. Brambilla, Psychopathological and personality traits underlie decision making in recent onset medication naïve anorexia nervosa: a pilot study. Psychiatry Res. 216, 89-96 (2014)

20. V.J. Geraedts, C. Dimopoulou, M. Auer, J. Schopohl, G.K. Stalla, C. Sievers, Health outcomes in acromegaly: depression and anxiety are promising targets for improving reduced quality of life. Front Endocrinol. 5, 229 (2015). doi:10.3389/fendo.2014. 00229

21. J. Tiemensma, A.A. Kaptein, A.M. Pereira, J.W. Smit, J.A. Romijn, N.R. Biermasz, Coping strategies in patients after treatment for functioning or nonfunctioning pituitary adenomas. J. Clin. Endocrinol. Metab. 96, 964-971 (2011)

22. J. Tiemensma, A.A. Kaptein, A.M. Pereira, J.W. Smit, J.A. Romijn, N.R. Biermasz, Affected illness perceptions and the association with impaired quality of life in patients with longterm remission of acromegaly. J. Clin. Endocrinol. Metab. 96, 3550-3558 (2011) 